\title{
New pathological findings in emphysema of childhood: 3. Unilateral congenital emphysema with hypoplasia- and compensatory emphysema of contralateral lung
}

\author{
R. HENDERSON, ALISON HISLOP, and LYNNE REID \\ Department of Experimental Pathology, Institute of Diseases of the Chest, Brompton Hospital, \\ London S.W.3
}

\begin{abstract}
A quantitative study is here reported on the lungs of a child of 9 months with unilateral emphysema associated with hypoplasia, and with compensatory emphysema in the contralateral lung. The left lung was judged to show congenital hypoplasia because of the reduced number of bronchi and arteries, its small volume, and a total alveolar number less than that normally found at birth. This last was due mainly to reduction in the number of acini, the intra-acinar number seeming little affected. As the alveoli were eight times the normal volume, the case was considered to be one of congenital hypoplastic emphysema.

The right lung was evidently normal at birth, since it had a normal number of bronchi, arteries, and alveoli. The lung was increased in volume due to an increase in alveolar volume-an example of compensatory emphysema.

This case is discussed with relation to two previously reported cases of lobar emphysema and other cases in the literature. It is emphasized that a quantitative analysis of the state of bronchi, alveoli, and blood vessels is important to establish the nature of the pathological change. A preliminary classification based on the anatomical features is offered.
\end{abstract}

The degree of growth of airways, alveoli, and arteries in cases of childhood lobar emphysema has recently been assessed quantitatively. In one case the condition was due to a 'polyalveolar' lobe (Hislop and Reid, 1970) and in another to overinflation of a normally developed lobe (Hislop and Reid, 1971). In the first paper (Hislop and Reid, 1970) methods for analysing lung growth precisely were described.

The purpose of this report is to describe a case of unilateral emphysema in an infant whose lungs were examined at 9 months of age. The application of quantitative methods revealed that the emphysema in the left lung was part of antenatal hypoplasia that affected airways as well as alveoli -and hence a 'congenital' emphysema. The contralateral lung had increased to above normal volume and the quantitative methods have been applied for the first time to assessing the compensatory emphysema that had developed in the lung during the time of most active alveolar growth. The presence of a ventricular septal defect affected certain aspects of the arterial system.

\section{CASE HISTORY}

This baby was born on 17 March, 1965. She had a cleft lip and anterior palate. She was seen at 6 months for repair of the lip but only a limited repair was considered possible because of her poor physical condition. At this time she was thought to have an enlarged left ventricle with a loud systolic murmur at the left sternal edge together with a murmur at the apex interpreted as being due to increased blood flow.

The radiograph on 3 September, 1965 (Fig. 1) was in partial expiration, the left dome being low compared with the right, suggesting air trapping in the left lung, although the heart was not displaced : the left lung was hypertransradiant and avascular, these changes being least marked in the medial part of the left upper lobe where the blood flow seemed better but still not normal. The right lung was plethoric, the heart and pulmonary trunk enlarged, and the aortic knuckle small. The apical lower lobe was partially collapsed. Angiography confirmed that the vessels to the right lung were enlarged with dilatation and tortuosity mainly of the proximal intrapulmonary vessels. No medium entered the left lung; an infracristal septal defect was seen. 


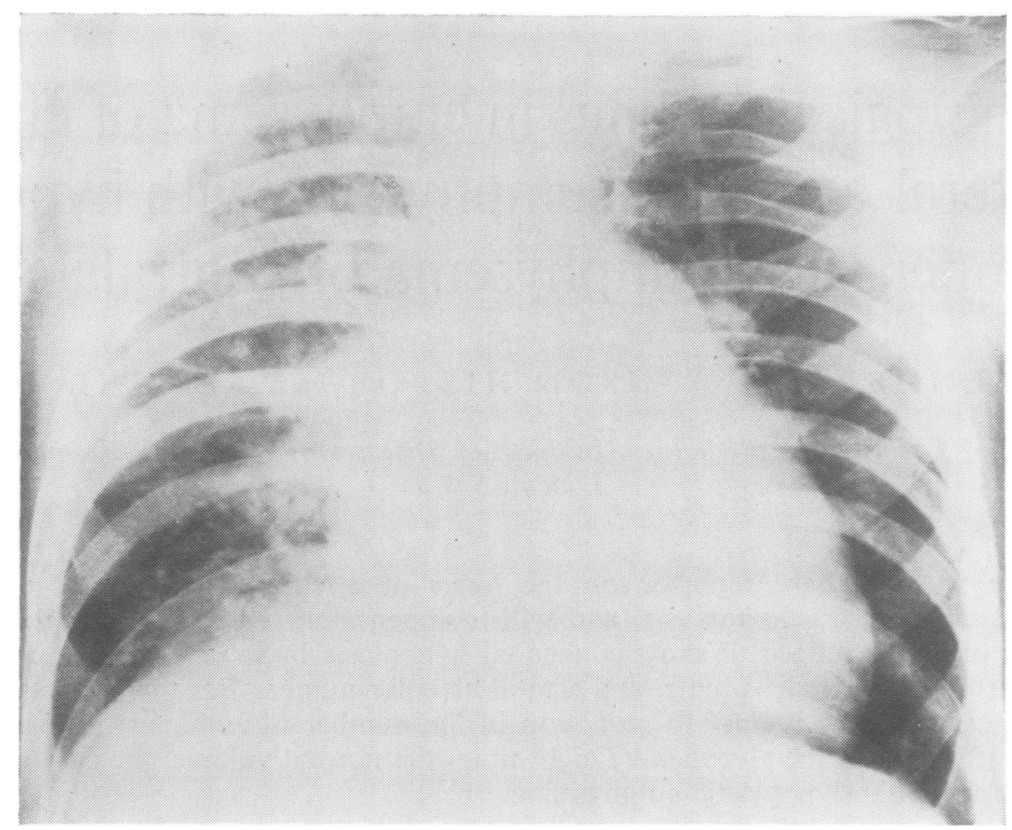

FIG. 1. Postero-anterior radiograph showing hypertransradiant left lung with heart in midline but low left dome of diaphragm suggesting air trapping. Right lung congested with some collapse of the apical lower lobe. Heart and main pulmonary artery enlarged.

Two months later the child was again admitted to hospital because of dyspnoea which it was thought might be due to an emphysematous left lung. On the radiograph the plethora appeared worse but the region of collapse had reaerated. Cardiac catheter studies carried out at Westminster Hospital on 24 November, 1965, showed a ventricular septal defect with a moderate left-to-right shunt together with a marked degree of pulmonary hypertension.

The pressure in the right ventricle was 70/14 and in the pulmonary artery $77 / 30 \mathrm{mmHg}$. Estimated oxygen consumption was $56 \mathrm{ml} /$ unit, giving a systemic flow of $1.21 / \mathrm{min}$, a pulmonary flow of $2.41 / \mathrm{min}$, and a pulmonary vascular resistance of 1,665 dyn $\mathrm{sec} / \mathrm{cm}^{5}$.

Two weeks after the catheter studies the child became very dyspnoeic with poor air entry and wheezing heard over the left chest, and several days later, on 9 December, 1965, a left pneumonectomy and banding of the right pulmonary artery was performed. The band was subsequently removed because it was thought that by slipping it had been responsible for the cardiac arrest which had occurred on the child's return to the ward and which was successfully treated.

Although initially she was better, by 11 December the respirations became more laboured and she again had a cardiac arrest. The chest was reopened and after the heart was restarted the band was reappliec. in an attempt to reduce the compliance of the righ lung. After an initial improvement postoperativel she had a further cardiac arrest and died.

\section{RESULTS}

Both lungs are described here although the left was removed surgically five days before the right lung and heart were obtained at necropsy. No ob? struction was seen in the airways of either lung.

LEFT LUNG When received in the laboratory the left lung had deflated in the region around the hilum but most of the upper lobe and part of the्w diaphragmatic surface still appeared emphys sematous with air trapping.

Two small pulmonary arteries were found at the hilum and these were individually injected wittion Micropaque barium suspension (Fig. 2A). The pulmonary arteries at the hilum were considerabls smaller than those in the right lung and thळ amount of peripheral filling was also much less.

The cut surface of the left lung showed no evidence of disease (Fig. 3) but in the upper lobe the air spaces of the lung were enlarged, for the 

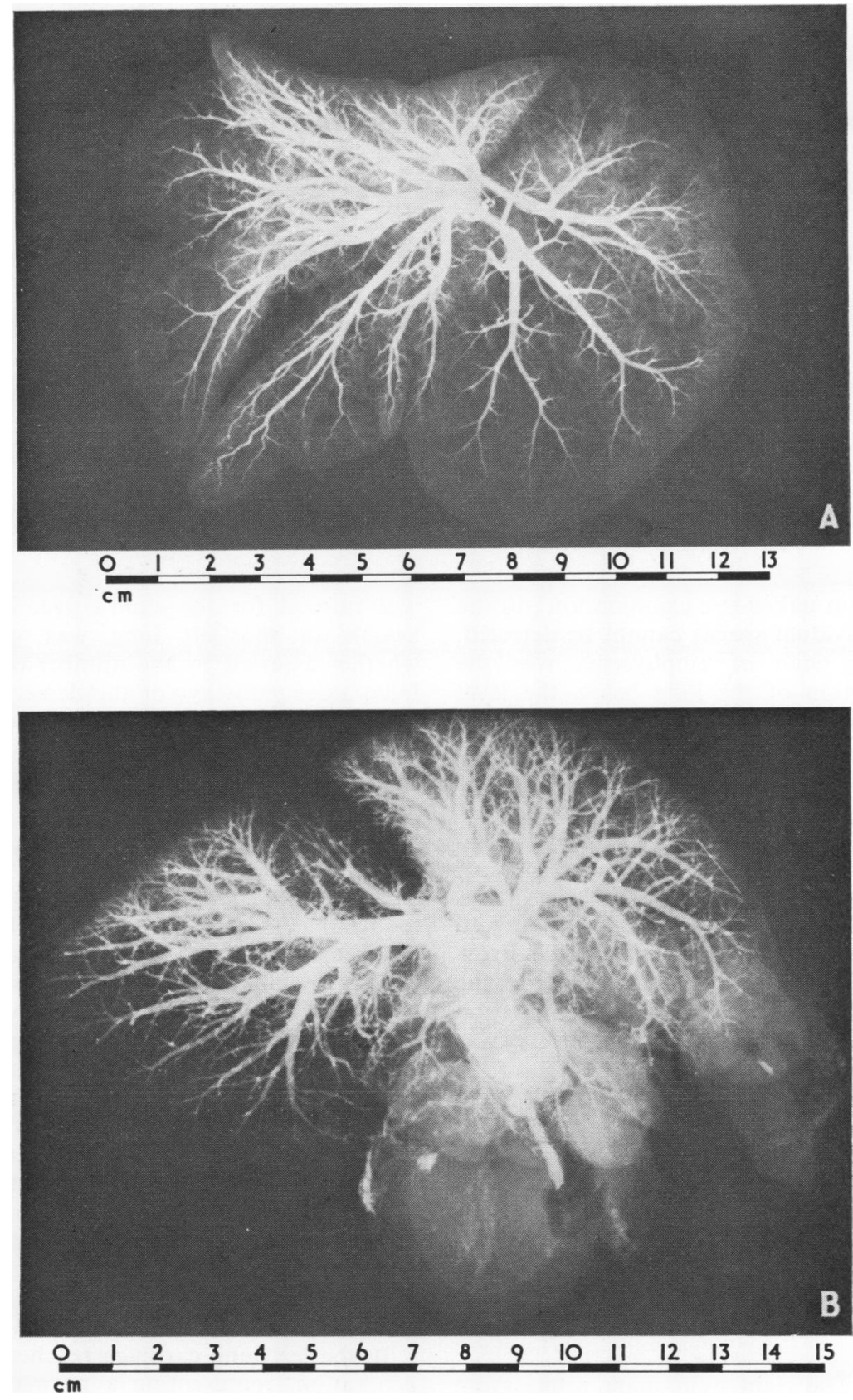

FIG. 2. Arteriogram of $(A)$ the left lung; all arteries are narrower and with fewer side branches than normal: $(B)$ the right lung; main artery is of normal diameter for lung volume, the only abnormality being 'pruning' in the subpleural few millimetres. 


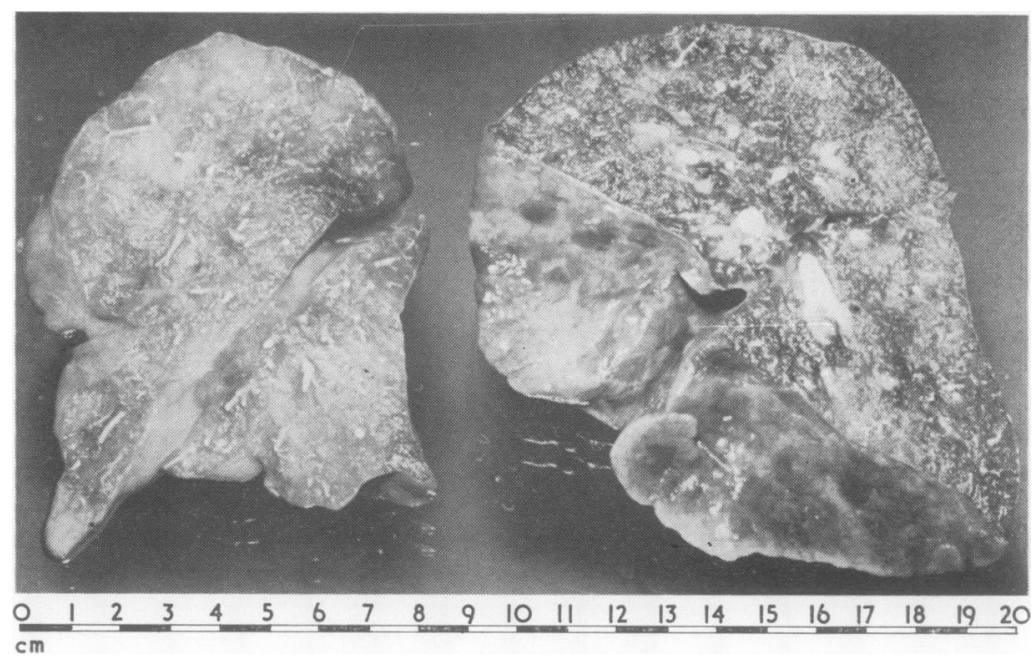

FIG. 3. Cut surface of left and right lungs each halved sagittally: in the smaller left lung arteries are very much narrower.

were detectable on naked-eye examination ; in the normal lung individual spaces cannot be detected. Another striking sign of emphysema was the degree of retraction of the lung below the level of the cut surface, the airways and blood vessels becoming unduly prominent and the pleura wrinkled (Reid, 1967).

RIGHT LUNG AND HEART A tape had been applied to the pulmonary artery just above the level of the valves. The main pulmonary artery was dilated and passed to the left before bending to become the right pulmonary artery: the narrow left pulmonary artery arose from the back of the dilated main artery so that on first examination it seemed that the main pulmonary artery was the left.

The arteries of the right lung (Fig. 2B) were injected through a cannula tied in the right ventricle. When cut, the lung did not retract below the surface (Fig. 3), no wrinkling of the pleura occurred, and individual air spaces were not detected.

The volume of the left lung after inflation was $135 \mathrm{ml}$, that of the right under the same condition $250 \mathrm{ml}$.

ARTERIOGRAMS The right pulmonary arteriogram (Fig. 2B) seemed normal save for some reduction in the filling in the subpleural few millimetres. The segmental pattern of the left arteriogram (Fig. 2A) was normal but the size of the left pulmonary artery was half that of the right which was normal for the child's age. The number of vessels in the left lung was greatly reduced whether assessed by the number of side branches from axial pathways or the density of vessels per $\mathbb{D}$ unit area of the arteriogram. The sparseness of the vessel pattern was more obvious in the upper than in the lower lobe. At the periphery of the left lung the vessels were smaller and fewer than in the right.

Airways number (right lung-normal ; left lungreduced) An airway to the posterior segment of the left lower lobe was traced by dissection-only the sixth generation was reached before the air- $\delta$ way became too small to be followed further, and $\frac{3}{3}$ this just over half a centimetre from the pleura. 0 In a normal lung double this number could be traced. In a pathway to the anterior segment of $\frac{}{0}$ the same lobe, the eighth generation was reached. Serial section of the last half centimetre of the $N$ first pathway showed four additional branches $N$ before the terminal bronchiolus, making 10 in all. N In a pathway to the right lower lobe, the 13th generation was reached by dissection and a total $<$ of 21 was seen after microscopic study of serial sections. This is within the normal range.

In the left lung cartilage reached to the seventh generation, representing a normal proportion of 0 the reduced airway number: in the right it was $\mathbb{\mathbb { D }}$ within the normal limits.

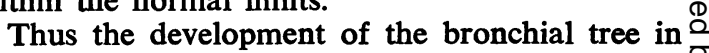
the right lung seemed normal, in the left severely hypoplastic. 
Alveolar number (right lung-normal ; left lungreduced) Microscopically the left lung showed emphysema but the large air spaces were irregularly distributed both through one acinus and in different parts of a section. No fibrosis or airway obstruction was seen: slight infiltration by inflammatory cells was the only abnormality of airways and alveoli. The blood vessels were obviously sparse and thick-walled with the elastic laminae showing the regular fetal arrangement.

The right lung showed smaller alveoli each with a more complex profile. The size of the air spaces varied rather more than in the normal. No fibrosis was seen.
The proportion of alveolar region in the lung on macroscopic point-counting was $81.2 \%$ in the left lung and $82.65 \%$ in the right, both within normal limits. The alveolar air comprised $60.9 \%$ of the alveolar region in the left lung and $56.7 \%$ in the right. These were both higher than the normal-54\%.

The total alveolar number (Fig. 4) for the left lung is $9.382 \times 10^{6}$, for the right $54.527 \times 10^{5}$. At this age the normal number for each lung is $58.8 \times 10^{6}$ (Dunnill, 1962), so that the number for the right lung is within normal limits, that for the left slightly lower than would be expected at birth.

The radial acinar count revealed for the left

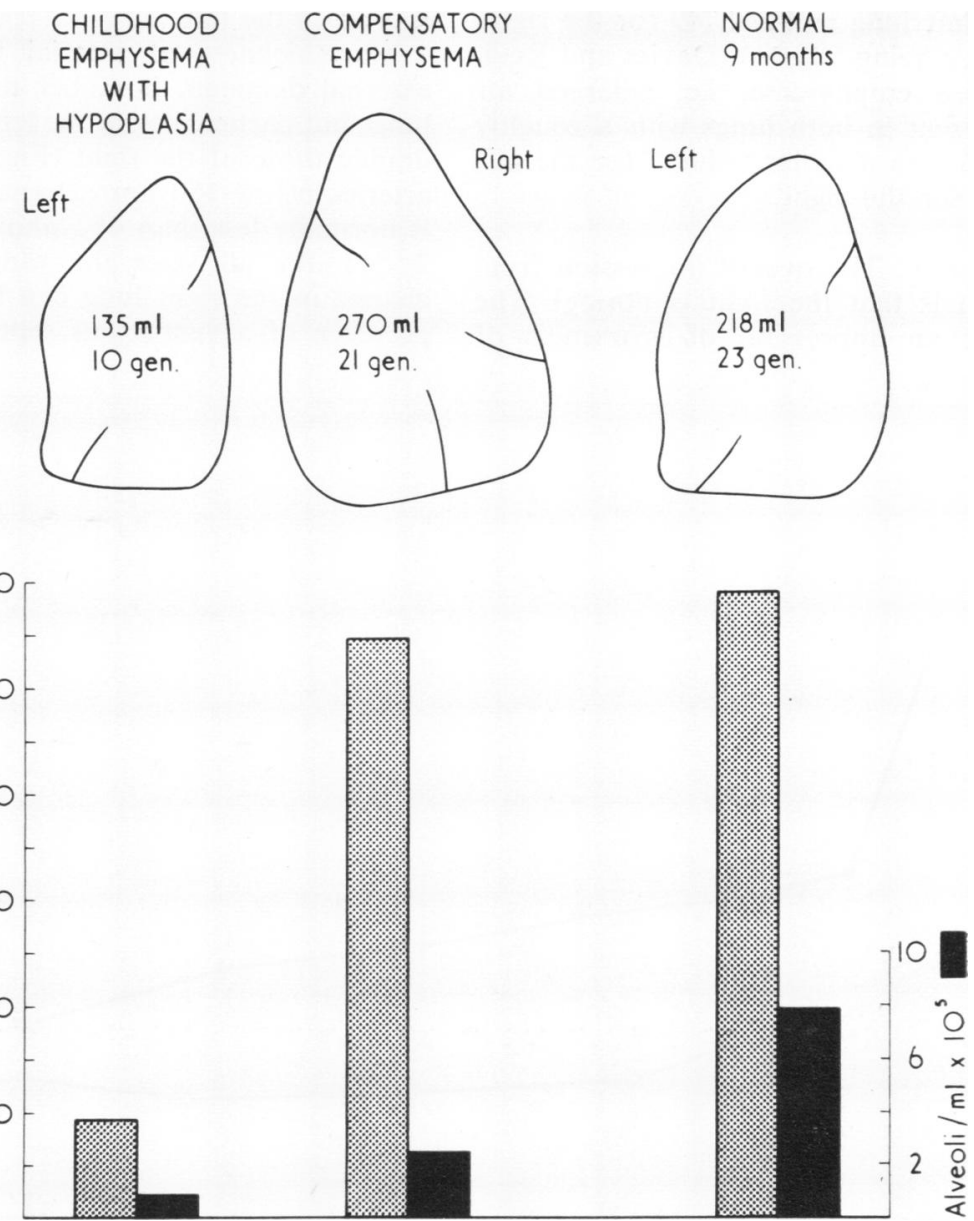

FIG. 4. Airway and alveolar findings compared with those in normal lung of nine months (Dunnill, 1962). Volume, airway and alveolar number of left lung reduced, alveolar size increased suggesting a hypoplastic emphysema. Airway and alveolar number for right lung normal, lung volume and alveolar size increased suggesting compensatory emphysema. 
lung an average of 5.94 alveoli to the edge of the acinus, and for the right 6.77 , the normal at this age being 6.6 (Emery and Mithal, 1960). Thus the right lung was normal, but the alveolar number on the left showed some slight reduction. Taken with the reduced total this suggests that the number of alveoli in the individual acinus is relatively normal, certainly much less reduced than the total alveolar number, and that the reduction in total alveolar number is caused mainly by a decrease in the total number of acini in the left lung.

The number of alveoli per millilitre in the alveolar region of the lung was also reduced for both lungs. In the present case the figure was only 85,586 for the left lung and 243,749 for the right, the normal value being 785,000 (Davies and Reid, 1970). Therefore emphysema, i.e. enlarged air spaces, was present in both lungs with a roughly nine-fold increase in alveolar volume for the left and three-fold for the right.

Pulmonary arteries The overall impression from the arteriogram is that the right is normal. The left lung gives an impression of sparseness of arteries. In the left lung the arterial lumen diameter (as assessed on the arteriogram) was reduced for the child's age, resembling that at $\frac{\bar{c}}{\bar{c}}$ birth and appropriate to a volume of $40-60 \mathrm{ml}$. The size of the artery to the right lung was normal 0 for a 10-month child, but since this lung was larger than is normal at this age, the artery was $\vec{\circ}$ small when judged by lung volume. For each lung the arterial size was appropriate to its alveolar $\omega_{\sigma}$

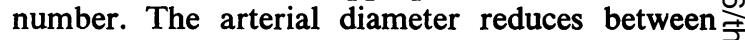
the hilum and the periphery in a normal fashion $x$ in each lung when judged by arterial diameter and $N$ measured at 25,50 , and $75 \%$ of the distance along ${ }^{N}$ an axial pathway. The length of the pathway is $\vec{c}$ within the normal range in the right lung but shorter in the left.

The thickness of arterial wall, as related to $\vec{z}$ external diameter, is higher than normal in both lungs but particularly in the left with values almost $\frac{\widehat{O}}{\sim}$ double those of the right (Fig. 5). At this age for $\overrightarrow{0}$ arteries below $150 \mu \mathrm{m}$ external diameter the wall $\stackrel{\oplus}{\vartheta}$ is normally less than $4 \%$, above $150 \mu \mathrm{m}$ less than $2.5 \%$ : for all sizes the range is narrow. The change in the right lung can be explained by the presence of a ventricular septal defect associated $\bar{\partial}$

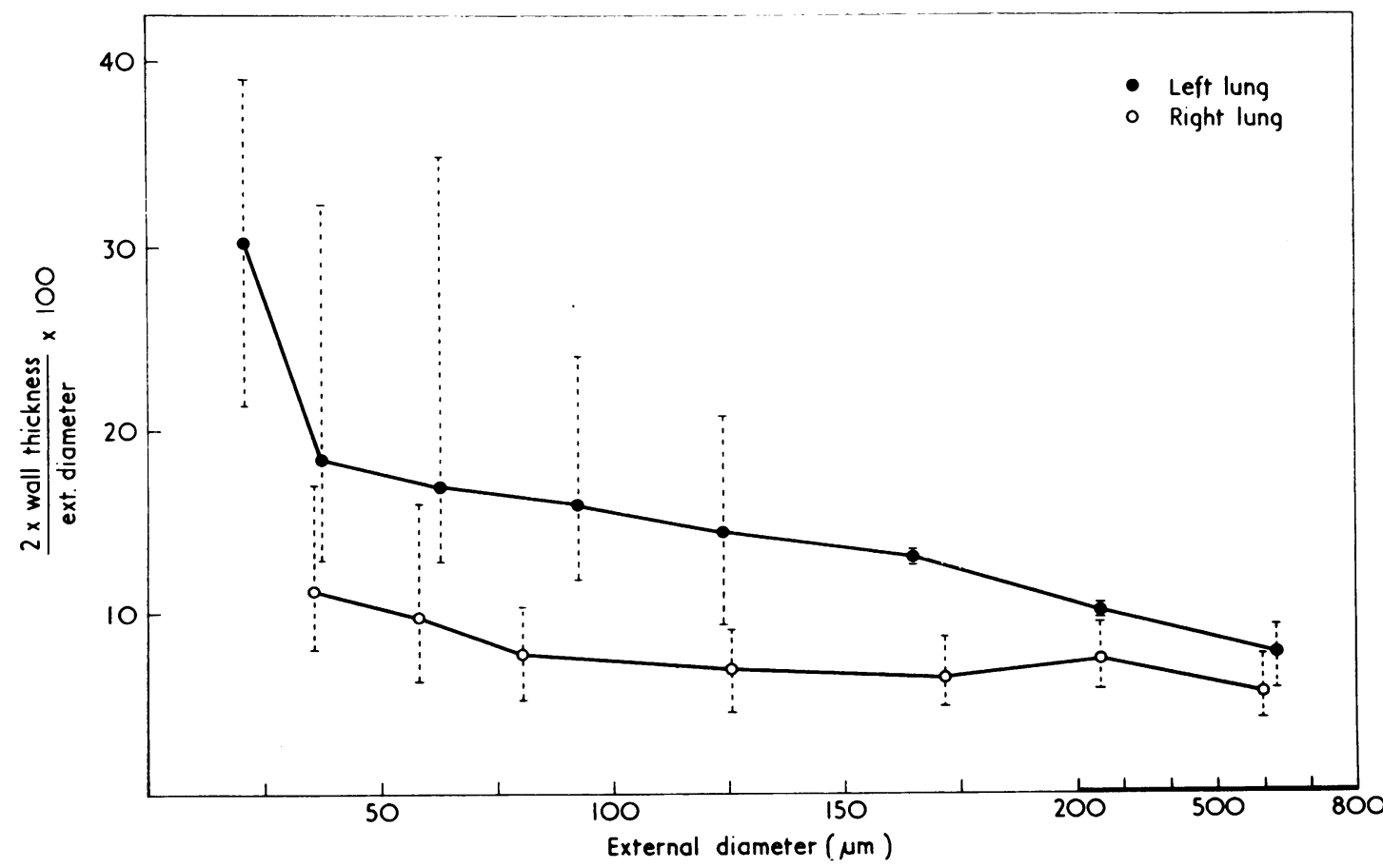

FIG. 5. Percentage wall thickness of arteries (grouped by external diameter) showing arteries more muscular than $\stackrel{\mathbb{Q}}{0}$ normal, particularly in the left where completely muscular structure is found in much smaller arteries. In the normal all values are below $4 \%$ (N.B. Scale above and below $200 \mu \mathrm{m}$ different $)$. 
with increased pulmonary blood flow and hypertension. This will be discussed further later: evidently some additional factor must be involved to explain the greater change in the left lung.

The population count of the small arteries (Fig. 6) showed an extension of muscle into smaller arteries at the periphery in both lungs; in the left it was more marked than in the right. The extension of muscle into arteries smaller than normal was also evident from the wall thickness plot shown in Figure 5.

In the right and left lungs the arteries accompanying identifiable airways were of the same size and at any given level about half the normal

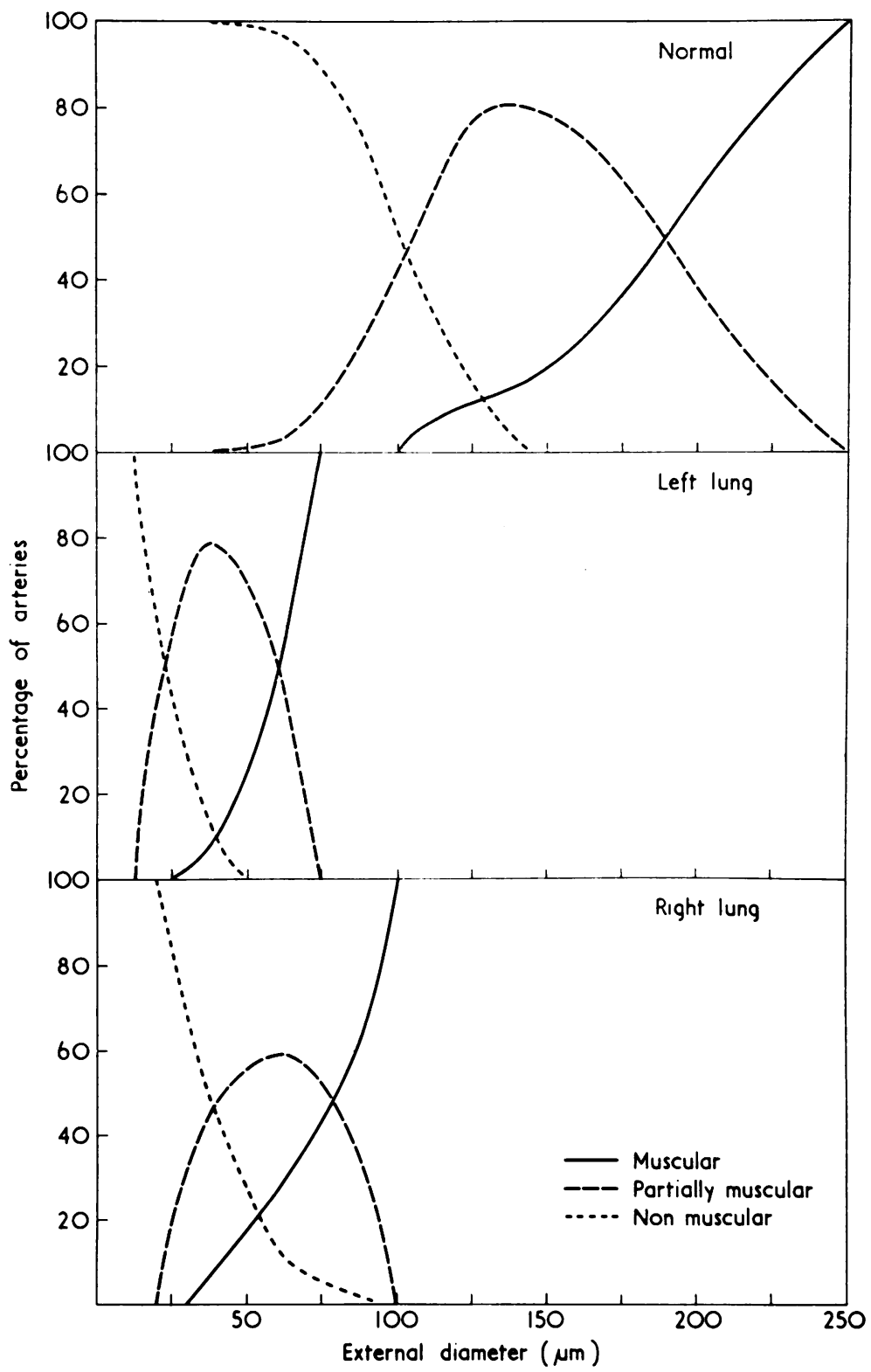

FIG. 6. Population count of small arteries showing similar abnormal pattern, in each lung, with muscle extending into much smaller arteries. 
diameter. This might be considered appropriate to the hypoplastic left lung arteries (see Fig. 2A) but represents an abnormal degree of reduction within the acinus for the right lung. In both lungs the intra-acinar arteries were far more muscular than normal with muscular arteries accompanying airways as distal as alveolar ducts. This means that within the acinus the size and structure of the arteries is similar on both sides, though the percentage wall thickness is higher in the left lung.

SUMMARY OF RESULTS The alveolar and airway findings for both lungs are summarized in Fig. 4 ; in the left lung the number of airways was greatly reduced, pointing to hypoplasia during intrauterine growth. The total alveolar number for the left lung was very low for the age of the child and less even than the normal number at birth. The number of alveoli per acinus seemed only slightly affected. Alveolar size was greatly increased, that is, the lung was emphysematous. The size of the main arterial pathways was much reduced for age but the number of branches was appropriate to the number of airways present. Thus the left lung showed congenital hypoplastic emphysema with associated hypoplasia of the airways: the pulmonary artery development was as might be expected from the alveolar and airway number.

In the right lung, airways, alveolar, and blood vessel numbers were normal but the increase in its volume to compensate for the small left lung had led to emphysema. Although the volume increase had occurred during a stage of active growth, the compensatory emphysema was not associated with increase in alveolar number or arterial size.

The extension of muscle into the acinus in both lungs was doubtless secondary to the ventricular septal defect.

\section{DISCUSSION}

\section{THE PRESENT CASE}

Hypoplastic emphysema In the present case emphysema in an infant has been shown to be part of a congenital hypoplasia of the lung. The disturbance in development seems to have affected only the left lung bud as the right lung must have developed normally before birth. The branches of the bronchial tree are equivalent in number to that of about 10 weeks of normal intrauterine development. As in a case of congenital diaphragmatic hernia studied in the same way (Kitagawa, Hislop, Boyden, and Reid, 1971), the number of alveoli per acinus is much less reduced than the $\stackrel{\overrightarrow{5}}{\stackrel{5}{0}}$ total number of alveoli, supporting the view that alveolar multiplication seems to be regulated by $\frac{\bar{\sigma}}{\bar{c}}$ acinar rather than total number.

In the present case it is not possible to be sure $\varnothing$ whether the number of alveoli at the time of death $\%$ developed before birth, the emphysema being $\overrightarrow{0}$ greatly accentuated after birth, or whether they had multiplied steadily through the intrauterine $\vec{\omega}$ and postnatal life of the child. The latter view is suggested by the fact that the number of alveoli $\vec{x}$ per acinus is closer to the normal for the age of $N$ the child than is the total alveolar number for $i$ this lung.

The low diaphragm on the left pointed to air ${ }^{\circ}$ trapping in this lung; and although this had not $\frac{}{5}$ displaced the heart, it suggests that air trapping $\overrightarrow{\vec{C}}$ may arise in a hypoplastic lung. That the patient

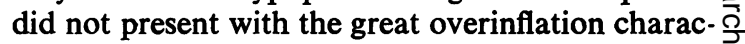
teristic of acute childhood lobar emphysema was $\overrightarrow{0}$ perhaps due to the enlarged heart or to the hypoplasia.

The emphysema of the left lung in this patient is only one manifestation of the hypoplasia affecting all structures in that lung. Unilateral hypo-o plasia as an isolated abnormality is usually diag-\% nosed radiologically, but as the affected lung is $\odot$ generally not transradiant (Simon, personal com- $\overrightarrow{0}$ munication) the hypoplasia must be different from 3 that seen in the present case.

It is unlikely that the emphysema was the cause of the child's dyspnoea ; any contribution that it may have made was probably minor compared응 with that of the congenital heart lesion.

Although in this case the whole of one lung was affected, hypoplasia may cause a condition. presenting clinically as lobar emphysema. In such a case (case 12, Reid, 1967, p. 92) where childhood lobar emphysema was diagnosed from clinical and응 radiographic features, at thoracotomy part of the lobe was severely emphysematous on naked-eye examination, but neither the lobe nor the affectedn region was greatly increased in volume. This indicated that the alveoli were not only too larges -emphysema-but also too few-hypoplasia A preoperative angiogram showed that the artery to the affected region was narrower and witho fewer side branches than is normal.

Macleod's syndrome The case reported here presented as a unilateral hypertransradiant lung, of

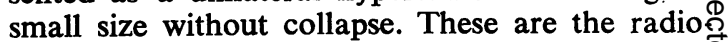
graphic features of Macleod's syndrome (1954 $\mathbb{B}$ but in the present case the pathogenesis is quite different from that of Macleod's syndrome seen in 
the adult in which the picture usually arises from an acquired lesion-a bronchiolitis obliterans patchily distributed through the lung-interfering with the postnatal alveolar multiplication. The bronchiolar lesions can be identified in the adult and there have been a growing number of cases in which the radiograph is known to have been normal before infection gave rise to a unilateral hypertransradiancy (i.e. Reid, Simon, Zorab, and Seidelin, 1967). A normal number of bronchial generations has been reported in the acquired condition (Reid and Simon, 1962). In the present case the number of airways was greatly reduced.

If this present child had lived to an older age, the radiograph would have been indistinguishable from that of Macleod's syndrome. Bronchography would probably have shown a lung with normal segmental arrangement but too few side branches. Without infection the irregularity of the bronchial wall and the bronchial occlusions that, in Macleod's syndrome, are evidence of inflammatory damage would not be expected.

The artery in this case was very small, whereas in Macleod's syndrome the reduction in size at the hilum is slight; it is flow that is strikingly reduced.

Compensatory emphysema The right lung in the present case is an example of compensatory emphysema. The increase in lung volume is due to an increase in alveolar size, but there was no increase in number, although the child was of an age when normal multiplication is fastest. The size of the main pulmonary artery was normal for the age and hence for the alveolar number, but not for the lung volume. The congenital heart lesion with secondary changes in blood flow and pressure in the lungs may have inhibited the response of the lung to overinflation, but it would seem unlikely to have reduced any additional alveolar multiplication since the lung was more plethoric than is normal. In so far as the behaviour of this lung is typical it would seem that compensatory overinflation, while associated with an increase in tissue volume and mass, is not associated either with an increase in the number of alveoli or with the diameter of the artery supplying the lung.

Effect of ventricular septal defect on pulmonary circulation Civin and Edwards (1950) were the first to report arterial changes associated with ventricular septal defect; they held the view that the increased flow leads first to persistence of the fetal arterial structure and then to hypertrophy of the arterial muscle coat. According to Kroop and Grishman (1950) and Dammann, Thompson, Sosa, and Christlieb (1960), there is also dilatation of arteries. Wagenvoort, Neufeld, DuShane, and Edwards (1961) showed that the amount of muscle in small vessels per unit area of lung was increased, and Naeye (1966), using planimetry, that this was due to an increase in the size of muscle cells, not in their number. Harrison (1958), from arteriograms and histological study, made the further observation that, whereas the proximal arteries were dilated, the lobular arteries were reduced in calibre.

We are currently applying the quantitative methods used in this study of emphysema to the lungs in cases of ventricular septal defect and have demonstrated that not all cases show similar structural changes in the pulmonary artery branches. Of the five cases studied in detail, only one showed a normal lumen diameter in the arteriogram as well as a reduction of intra-acinar artery size, as Harrison reported and as is seen in the right lung of the present case; but even this case differed from the present one in that muscle did not extend abnormally far into the acinus. Other cases showed a similar extension of muscle within the acinus as in the present case, but they differed in other respects. Correlation between the structural changes and the clinical and haemodynamic features of these cases of ventricular septal defect is the subject of a separate study. It seems then that the arterial changes in the right lung in the present case could be explained by the ventricular septal defect. In the left lung the hypoplasia doubtless contributes also.

\section{CHILDHOOD LOBAR EMPHYSEMA}

New pathological types and their recognition In a recent review of the histories of the 166 reported cases of childhood lobar emphysema, Murray (1967) concluded that 'at present the morphologic aspects and pathogenesis of congenital lobar emphysema are not clearly defined'. Raynor, Capp, and Sealy (1967) also emphasized that the pathological changes were perplexing and the pathogenesis poorly understood.

A quantitative analysis of the number and structure of airways, alveoli, and arteries present, as described in this series of patients, has revealed a striking difference in the pathological features of the various cases of childhood emphysema studied and has made it possible for some aspects of their pathogenesis to be deduced. 
Emphysema has been found to be associated with both hypoplasia and hyperplasia of the alveolar region and also to occur in a lobe containing the normal number of alveoli. It may not be possible to distinguish these types radiologically although hypertransradiancy in a normal-sized or small lung suggests a hypoplastic emphysema. Cases with mild or no symptoms may be those in which this mechanism has operated.

It is not possible to detect any radiographic difference between an overinflated normal lobe and a polyalveolar lobe even knowing the pathological diagnosis. In both, the lobe is hypertransradiant-that is, there is relatively more gas than blood or tissue. In the 'normal' lobe this is due to overinflation while in the 'polyalveolar' lobe although the blood vessels are normal for age they are small for the alveolar number, which suggests that the blood in the alveolar region is relatively reduced.

It is certainly worth analysing future cases by the methods that have been described here. From the clinical point of view it is important to discover whether the transradiant region represents an enlarged or relatively normal volume of lung. If the latter, then resection is probably not justified. Although it may not be possible to distinguish the polyalveolar from the normal but overinflated lobe, this does not matter clinically as the reason for resection is the compression of adjacent lung and shift of mediastinal structures, which can occur with either type.

It is certainly desirable that these types of emphysema be distinguished pathologically from each other to add to our understanding of this condition. For each pathological type of emphysema the age and sex incidence and lobar distribution should be established. The three cases of polyalveolar lobe described here were all in the left upper lobe, which raises the question whether the right middle and the lower lobes are ever polyalveolar.

Of the reported cases of childhood lobar emphysema, $14 \%$ were associated with cardiovascular malformations (Murray, 1967). In some series, such as those of Fischer, Potts, and Holinger (1952), it seems that a patent ductus arteriosus has produced mechanical obstruction. In another an abnormal vein or artery was thought to have produced the same effect (Contro, Miller, White, and Potts, 1958a and b). In other series, where the emphysema involved the right middle lobe, it could not be attributed to mechanical obstruction (Cottom and Myers, 1957 ; Jones et al., 1965). It may be that in these cases the emphysema is hypoplastic.

Method of lung examination The way in which the specimen was dissected and the various structures separately assessed was described in detail with the first case (Hislop and Reid, 1970). To establish the facts relevant to the interpretation of these cases of emphysema, it is perhaps worth describing the essential minimum examination-an estimation of alveolar number, alveolar size, and the number of bronchial branches arising from an axial pathway. The uniformity of any changes throughout the lobe or lung should be noted and both in dissection and in the selection of tissue allowance made for irregularity in distribution. If the changes are not uniform throughout the lobe the errors inherent in counting based on sampling might be expected to increase. This is to some extent counteracted by the smaller size of a child lobe than of an adult. The same number of blocks taken from each represents a much larger sample in the case of a child lung. During the first year of life the increase in alveolar number is great, about a third of a million a day. The differences between the normal and the various types of emphysema have proved so large that neither the problem of sampling nor the rapidly increasing alveolar number have prevented detection of the disturbance in disease.

Classification of childhood lobar emphysema Zatzkin, Cole, and Bronsther (1962) suggested that cases of childhood lobar emphysema should be divided into 'hypertrophic', in which no cause for the condition could be found, and 'obstructive', where some obstructive phenomenon could be identified. Murray (1967) felt that the evidence then available did not justify this view. It would seem possible, from the pathological types reported recently (Hislop and Reid, 1970, 1971), to formulate a preliminary subdivision of cases based on the anatomical findings.

Certainly it would seem better not to use the word 'hypertrophic'. In the case of adult disease the use of the word has caused much confusion, referring as it does to an increase in volume, which paradoxically is usually greatest where alveolar atrophy is most severe. The polyalveolar type of emphysema (Hislop and Reid, 1970) might reasonably be called a hypertrophy but the term 'polyalveolar' is more precise.

Atresia of a bronchus (Reid and Simon, 1964 ; Waddell, Simon, and Reid, 1965) may also present as a clinical emergency, because of increase 
in volume of the affected lobe, and be diagnosed as 'childhood lobar emphysema'. In all cases studied pathologically emphysema has been found. The affected segmental airways may be atretic but are not significantly reduced in number, indicating that the acinar number is probably virtually normal. The alveoli have not been counted in a newborn case of bronchial atresia but on the evidence of other cases it would be reasonable to suggest that as acinar number is normal the alveolar number at birth might also be expected to be normal. Collateral ventilation favours inspiration which reduces the blood flow and increases distensibility so that overinflation may occur and postnatal multiplication be impeded (Reid and Simon, 1964).

It would seem then that the clinical and radiological features of childhood lobar emphysema may arise from emphysema associated with any of the following combinations of anatomical abnormality at birth:

1. A normal number of bronchial generations -with an increased number of alveoli ("polyalveolar' lobe: Hislop and Reid, 1970)

2. A normal number of bronchial generations -with a normal number of alveoli (Hislop and Reid, 1971)

3. A reduced number of bronchial generations -with a reduced number of alveoli (the present case)

4. An atretic bronchial tree (number of bronchial generations probably normal)

-with ? a normal number of alveoli at birth

As alveolar multiplication after birth is so rapid, the two types described as having a normal alveolar number at birth may rapidly come to have too few alveoli for age if the postnatal alveolar multiplication is impaired.

We are grateful to Mr. C. Drew, Westminster Hospital, for letting us study this specimen, and to Dr. George Simon for his opinion on the radiographs.

\section{REFERENCES}

Civin, W. H., and Edwards, J. E. (1950). Pathology of the pulmonary vascular tree. I. A comparison of the intrapulmonary arteries in the Eisenmenger complex and in stenosis of ostium infundibuli associated with biventricular origin of the aorta. Circulation, 2, 545.

Contro, S., Miller, R. A., White, H., and Potts, W. J. (1958a). Bronchial obstruction due to pulmonary artery anomalies. I. Vascular sling. Circulation, 17, 418.

(1958b). Bronchial obstruction due to pulmonary artery anomalies. II. Pulmonary artery aneurysm. Circulation, 17, 424.

Cottom, D. G., and Myers, N. A. (1957). Congenital lobar emphysema. Brit. med. J., 1, 1394.
Dammann, J. F., Thompson, W. M., Sosa, O., and Christlieb, I. (1960). Anatomy, physiology and natural history of simple ventricular septal defects. Amer. J. Cardiol., 5, 136.

Davies, G. M., and Reid, L. (1970). Growth of alveoli and pulmonary arteries in childhood. Thorax, 25, 669.

Dunnill, M. S. (1962). Postnatal growth of the lung. Thorax, $17,329$.

Emery, J. L., and Mithal, A. (1960). The number of alveoli in the terminal respiratory unit of man during late intrauterine life and childhood. Arch. Dis. Childh., 35, 544.

Fischer, H. W., Potts, W. J., and Holinger, P. H. (1952). Lobar emphysema in infants and children. J. Pediat., 41, 403.

Harrison, C. V. (1958). The pathology of the pulmonary vessels in pulmonary hypertension. Brit. J. Radiol., 31, 217.

Hislop, A., and Reid, L. (1970). New pathological findings in emphysema of childhood. I. Polyalveolar lobe with emphysema. Thorax, 25, 682.

- (1971). New pathological findings in emphysema of childhood 2. Overinflation of a normal lobe. Thorax, 26, 190.

Kitagawa, M., Hislop, A., Boyden, E. A., and Reid, L. (1971). Lung hypoplasia in congenital diaphragmatic hernia: a quantitative study of airway, artery and alveolar development. Brit. J. Surg. (In the press.)

Jones, J. C., Almond, C. H., Snyder, H. M., Meyer, B. W., and Patrick, J. R. (1965). Lobar emphysema and congenital heart disease in infancy. $J$. thorac. cardiovasc. Surg., 49, 1.

Kroop, I. G., and Grishman, A. (1950). Isolated interventricular septal defect with dilatation of the pulmonary artery. Amer. Heart J., 40, 125.

Macleod, W. M. (1954). Abnormal transradiancy of one lung. Thorax, 9, 147.

Murray, G. F. (1967). Congenital lobar emphysema. Surg. Gynec. Obstet., 124, 611 .

Naeye, R. L. (1966). The pulmonary arterial bed in ventricular septal defect. Anatomic features in childhood. Circulation, 34, 962.

Raynor, A. C., Capp, M. P., and Sealy, W. C. (1967). Lobar emphysema of infancy. Diagnosis, treatment, and etiological aspects. Ann. thorac. Surg., 4, 374.

Reid, L. (1967). The Pathology of Emphysema. Lloyd-Luke, London.

and Simon, G. (1962). Unilateral lung transradiancy. Thorax, 17, 230.

_ (1964). The role of alveolar hypoplasia in some types of emphysema. Brit. J. Dis. Chest, 58, 158.

Zorab, P. A., and Seidelin, R. (1967). The development of unilateral hypertransradiancy of the lung. Brit. J. Dis. Chest, 61, 190.

Waddell, J. A., Simon, G., and Reid, L. (1965). Bronchial acresia of the left upper lobe. Thorax, 20, 214.

Wagenvoort, C. A., Neufeld, H. N., DuShane, J. W., and Edwards, J. E. (1961). The pulmonary arterial tree in ventricular septal defect. A quantitative study of anatomic features in fetuses, infants, and children. Circulation, 23, 740.

Zatzkin, H. R., Cole, P. M., and Bronsther, B. (1962). Congenital hypertrophic lobar emphysema. Surgery, 52, 505. 